\title{
SISTEM INFORMASI PENJUALAN IKAN CUPANG BERBASIS WEB DI CALS.BETTAQUEENS JAKARTA PUSAT
}

\author{
${ }^{1}$ Firda Mayang Sari, ${ }^{2}$ Andi Arfian \\ ${ }^{1,2,3}$ Progam Studi Sistem Informasi, Universitas Nusa Mandiri \\ Nusa Mandiri Tower, Jl. Jatiwaringin Raya No.2 Jakarta Timur \\ firdamayangsari10@gmail.com,andi.afn@nusamandiri.ac.id
}

Received: October 21, 2021, Revised: October 24, 2021 Accepted: October 25, 2021

\begin{abstract}
Abstrak
Tujuan dari penelitian ini adalah untuk meracang aplikasi penjualan dan desain sistem penjualan berbasis web pada Cals.Bettaquens. Hal ini dibuat untuk meningkatkan keuntungan dan memberikan kemudahan bagi pelanggan untuk memesan dan membeli helm. Metode ini menggunakan pengumpulan data, analisis (dengan survei, wawancara dan studi pustaka ) dan desain (bentuk masukan, proses, laporan, dan database). Hasil dari penelitian ini adalah sistem penjualan berbasis web yang dapat digunakan oleh pelanggan 24 jam. Kesimpulannya adalah sistem penjualan berbasis web memiliki fasilitas seperti halaman informasi, halaman order, dan membatalkan halaman.
\end{abstract}

Kata kunci: Sistem Infromasi, Penjualan, Web

\section{Abstract}

The purpose of this research is to design a sales application and web-based sales system design on Cals.Bettaquens. It is designed to increase profits and make it easier for customers to order and buy helmets. This method uses data collection, analysis (by surveys, interviews and literature studies) and design (input forms, processes, reports, and databases). The result of this research is a web-based sales system that can be used by customers 24 hours. The conclusion is that the web-based sales system has facilities such as information pages, order pages, and equation pages.

Keywords: Information Systems, Sales, Web

\section{$1 \quad$ Pendahuluan (or Introduction)}

\subsection{Latar Belakang}

Teknologi data ketika ini mampu membuka mata seluruh orang di dunia, merupakan terdapat hubungan baru, tempat pemasaran baru, serta jaringan usaha kelas dunia tanpa batasan. Toko Cals.bettaqueens Jakarta pusat artinya sesuatu perjuangan yang bergerak di dibidang penjualan ikan cupang yg beralamat di Jalan Taman Lagura Indah Jakarta Pusat. ketika ini penjualan ikan cupang dilakukan secara tradisional, artinya bertemunya antara pembeli serta penjual, serta dicoba pula pada media jejaring sosial.

\subsection{Perumusan Masalah}

1. Bagaimana sistem berita penjualan di Cals.bettaqueens Jakarta pusat.

2. Bagaimana membentuk sistem info penjualan yg bisa di akses secara online.

3. Bagaimana membentuk sistem berita penjualan buat melaksanakan pemesanan ikan secara online.

\subsection{Maksud dan Tujuan}

Tujuan yg hendak dicapai dari pembangunan sistem berita penjualan berbasis website di Cals.bettaqueens Jakarta pusat ini artinya :

\section{c) (1) (2) (-)}


1. Mempermudah konsumen melakukan pemesanan produk.

2. Memperluas jaringan pemasaran produk yang dicoba oleh Cals.bettaqueens Jakarta pusat.

3. Menciptakan media pemasaran yg lebih efisien, interaktif dan informatif.

\section{Tinjauan Literatur (or Literature Review)}

\subsection{Sistem}

Sistem merupakan kumpulan dari elemen-elemen yang bekerjasama buat menggapai satu tujuan eksklusif. Sistem data adalah sesuatu sistem di pada sesuatu organisasi yang mempertemukan kebutuhan pengolahan transaksi setiap hari yang menunjang guna pembedahan organisasi yang bersifat manajerial menggunakan kegiatan strategi berasal sesuatu organisasi buat mampu sediakan pada pihak luar tertentu menggunakan laporan-laporan yang dibutuhkan.

\subsection{Penelitian Terkait}

Penelitian yang dilakukan (suminten,2020) menggunakan judul "Sistem informasi Penjualan software Kasir Berbasis Website di Mart Serba Guna Blora". Penelitian dilakukan untuk mengetahui pelayanan kasir Mart Serba Guna yang masih dilakukan secara manual saat melakukan penginputan data sebagai akibatnya mengakibatkan antrian pelanggan yang menumpuk. Selain itu sistem manual mempunyai banyak kelemahan diantaranya kebanyakan terjadi kesalahan di pencatatan, serta pencarian data yang sulit sebab setiap dilakukan mencari data penjual wajib mencari pada buku akbar.

\section{$3 \quad$ Metode Penelitian (or Research Method)}

Teknik Pengumpulan Data

\section{Observasi}

Penulis memandang secara langsung di Toko Cals.bettaqueens Jakarta Pusat Jalan Taman Lagura Indah serta melaksanakan pengamatan pada bagian penjualan, sehingga memperoleh cerminan yang lengkap serta jelas menimpa prosedur penjualan, prosedur penjualan di Toko Cals.bettaqueens Jakarta Pusat.

2. Wawancara

Penulis melaksanakan tanya jawab dengan bagian penjualan serta Bapak Franky sebagai owner Toko Cals.bettaqueens Jakarta Pusat tentang permasalahan yang masih kurang jelas pada dikala melaksanakan observasi, tidak hanya itu penulis pula melaksanakan wawancara dengan konsumen yang berkunjung ke Toko Cals.bettaqueens Jakarta Pusat

Model Pengembangan Sistem

Model pengembangan sistem yang digunakan dalam riset ini memakai model Waterfall ataupun air terjun merupakan model yang dibesarkan buat pengembangan perangkat lunak. Model tumbuh secara sistematis dari satu sesi ke sesi lain dalam mede semacam air terjun.

1. Analisa Kebutuhan Software

Kebutuhan pada web ini ialah data pengolahan informasi penjualan Ikan Cupang Cals.bettaqueens Jakarta Pusat ialah input informasi produk, input informasi konsumen, input informasi pembelian oleh konsumen hingga dengan hasil pengolahan informasi penjualan, input informasi pengiriman serta laporan penjualan yang bisa dilihat oleh owner Toko Cals.bettaqueens Jakarta Pusat.

2. Desain

Dalam merancang web ini penulis menggunakan pemrograman beroreantasi objek serta mengkategorikan 2 tools ialah tools system serta tools application, pada tools system memakai Unified Modelling Language (UML) meliputi Use Case Diagram serta Activity Diagram. Untuk desain databasenya menggunakan Entity Relation Diagram (ERD).

\section{Hasil dan Pembahasan (or Results and Analysis)}

Sistem penjualan secara online berbasis web dimana penjual dan pembeli dapat melakukan transaksi tanpa harus bertatap muka langsung. Pelanggan melakukan transaksi pembelian melalui media browser dengan jaringan internet. Berikut adalah spesifikasi kebutuhan (system requirement) dari sistem informasi penjualan : 
Halaman Pelanggan :

A1. Pelanggan bisa melakukan login

A2. Pelanggan bisa melihat produk

A3. Pelanggan bisa membeli produk

A4. Pelanggan bisa melihat dagtar pesanan di keranjang belanja

A5. Pelanggan bisa meng-update jumlah dari item yang dipesan

A6. Pelanggan bisa menghapus produk yang dipesan

A7. Pelanggan dapat melakukan pembayaran

A8. Pelanggan bisa melihat nominal yang harus dibayar

A9. Pelanggan bisa melakukan logout

Halaman Administrasi :

B1. Admin bisa melakukan login

B2. Admin dapat melihat list produk

B3. Admin dapat mengedit data produk

B4. Admin dapat menghapus produk

B5. Admin dapat melihat list data pelanggan

B6. Admin dapat menghapus data pelanggan

B7. Admin dapat melihat list pemesanan

B8. Admin dapat menghapus data pesanan

B9. Admin dapat melihat bukti pembayaran

B10. Admin dapat menginput data produk baru

B11. Admin dapat melihat laporan data pembelian produk

B12. Admin dapat melakukan logout

\begin{tabular}{|c|c|}
\hline Use Case Name & Halaman Pelanggan \\
\hline Requirements & A1-A9 \\
\hline Goal & $\begin{array}{l}\text { Pelanggan melakukan login dan melakukan belanja } \\
\text { secara online melalui website }\end{array}$ \\
\hline Pre-conditions & Pelanggan telah melakukan login \\
\hline Post-conditions & Pelanggan bisa membeli barang secara online \\
\hline Failed End Condition & Pelanggan membatalkan belanja secara online \\
\hline Primary Actors & Pelanggan \\
\hline Main Flow / Basic Path & $\begin{array}{l}\text { 1. Pelanggan bisa melakukan login } \\
\text { 2. Pelanggan bisa melihat produk } \\
\text { 3. Pelanggan bisa membeli produk } \\
\text { 4. Pelanggan bisa melihat dagtar pesanan di } \\
\text { keranjang belanja } \\
\text { 5. Pelanggan bisa meng-update jumlah dari item } \\
\text { yang dipesan } \\
\text { 6. Pelanggan bisa menghapus produk yang dipesan } \\
\text { 7. Pelanggan dapat melakukan pembayaran } \\
\text { 8. Pelanggan bisa melihat nominal yang harus } \\
\text { dibayar } \\
\text { 9. Pelanggan bisa melakukan logout }\end{array}$ \\
\hline Invariant & - \\
\hline
\end{tabular}

\begin{tabular}{|l|l|}
\hline Use Case Name & Admin Melakukan List Produk \\
\hline Requirements & B2-B8 \\
\hline Goal & Admin dapat melakukan List Produk \\
\hline Pre-conditions & Admin telah melakukan login \\
\hline Post-conditions & $\begin{array}{l}\text { List Produk terupdate, terubah, terhapus, } \\
\text { terverifikasi }\end{array}$ \\
\hline
\end{tabular}


https://jurnal.amikwidyaloka.ac.id/index.php/awl jurnal@amikwidyaloka.ac.id / editor.jurnalwidya@gmail.com

\begin{tabular}{|l|l|}
\hline Failed End Condition & Gagal mengubah list produk \\
\hline Primary Actors & Administrator \\
\hline Main Flow / Basic Path & $\begin{array}{l}\text { 1. Admin dapat melihat list produk } \\
\text { 2. Admin dapat melihat list data pelanggan } \\
\text { 3. Admin dapat melihat list pemesanan }\end{array}$ \\
\hline Invariant & 2a. Admin dapat mengedit data produk \\
& 2b. Admin dapat menghapus produk \\
& 3c. Admin dapat menghapus data pelanggan \\
& 4d. Admin dapat menghapus data pesanan \\
\hline
\end{tabular}

\section{$5 \quad$ Kesimpulan (or Conclusion)}

Dalam perancangan website penjualan ikan cupan di Cals.Bettaqueens dan hasil pengamatan penulis lakukan, maka penulis menyimpulkan bahwa :

1. Melalui website penjualan pelanggan dapat lebih mudah untuk melakukan pemesanan dan mengetahui informasi tentang produk - produk yang ada di web Cals.Bettaqueens.

2. Sistem informasi penjualan ikan cupang aplikasi berbasis web dan memuat database pengolahan data produk dan penjualan secara terpusat sehingga dapat mempermudah pengelolaan data produk dan laporannya.

3. memberikan kemudahan kepada pelanggan dalam pemesanan produk yang dapat diakses melalui website dengan alamat https://cals-bettaquesns.xyz/

\section{Referensi (Reference)}

[1] Suminten, "Sistem Informasi Penjualan Aplikasi Kasir Berbasis Website Pada Mart Serba Guna Blora," in Prosisko, vol. 7, no. 2, 2020, pp. 102-107.

[2] Lubis Adyanata, Basis data dasar untuk mahasiswa ilmu komputer Yogyakarta: CV.Budi Utama. Yogyakarta: CV. Budi Utama, 2016.

[3] S. Monalisa et al., "Rancang Bangun Sistem Informasi Inventory Obat Pada Rumah Sakit Jiwa Tampan Berbasis Web," Jurnal Sistem Informasi, vol. 02, no. 02. pp. 2579-5341, 2018, [Online]. Available: http://jurnal.uinsu.ac.id/index.php/query/article/view/2610.

[4] N. Jurdam, "Perancangan Sistem Informasi Rental Mobil Berbasis Web Pada PT.APM Rent Car," J. IntraTech, vol. 2, no. 2, pp. 64-77, 2014.

[5] A. Praelsetyo and R. Susanti, "Sistem Informasi Penjualan Berbasis Web Pada PT. Cahaya," in Jurnal Ilmiah Teknologi Informasi Asia, vol. 10, no. 2, 2016, pp. 1-16.

[7] Manganugrahana, Y. (2019). Pengertian XAMPP Lengkap dengan Cara Menggunakannya (Terbaru). https://www.niagahoster.co.id/blog/cara-menggunakan-Xampp/\#Pengertian_XAMPP

[8] Mountaines, P. E., Satoto, K. I., \& Kridalukmana, R. (2013). Pengembangan Aplikasi Berbasis Web untuk Menampilkan Absensi dan Nilai Akhir Peserta Didik (Studi Kasus di SMP Negeri 32 Semarang). Jurnal Teknologi Dan Sistem Komputer, 1(4), 129-144. https://doi.org/10.14710/jtsiskom.1.4.2013.129-144

[9] Saragi Napitu, R. C., Ramadhani, I. A., \& Firman, F. (2020). Perancangan Sistem Absensi Berbasis Web pada Program Studi PTI UNIMUDA Sorong. JURNAL PETISI (Pendidikan Teknologi Informasi), 1(2), 1-7. https://doi.org/10.36232/jurnalpetisi.v1i1.453

[10] Subiantoro, \& Sardiarinto. (2018). Perancangan Sistem Absensi Pegawai Berbasis Web. Jurnal Swabumi, 6(2), 184-189.

[11] Triyono, T., Safitri, R., \& Gunawan, T. (2018). Perancangan Sistem Informasi Absensi Guru Dan Staff Pada Smk Pancakarya Tangerang Berbasis Web. SENSI Journal, 4(2), 153-167. https://doi.org/10.33050/sensi.v4i2.638

[12] Adi Mardian, Thomas Budiman, Rachmawaty Haroen; Verdi Yasin (2021), Perancangan Aplikasi Pemantauan Kinerja Karyawan Berbasis Android di PT. Salestrade Corp. Indonesia, "Jurnal Manajemen Informatika Jayakarta", E-ISSN : 2797-0930 (Online), P-ISSN : 2746-5985 (Print), Volume 1, Nomor 3,Juli 2021, halaman 169-185, DOI: 10.52362/jmijayakarta.v1i3.481 , URL Publikasi: 
https://jurnal.amikwidyaloka.ac.id/index.php/awl

jurnal@amikwidyaloka.ac.id / editor.jurnalwidya@gmail.com

http://journal.stmikjayakarta.ac.id/index.php/JMIJayakarta/article/view/481

[13] Nandang Mulyana, Agus Sulistyanto, Verdi Yasin (2021), Perancangan sistem informasi pengelolaan aset it berbasis web pada pt mandiri axa general insurance, "Jurnal Manajemen Informatika Jayakarta", EISSN : 2797-0930 (Online), P-ISSN : 2746-5985 (Print), Volume 1, Nomor 3, Juli 2021, halaman 243257, DOI: 10.52362/jmijayakarta.v1i3.498, URL Publikasi: http://journal.stmikjayakarta.ac.id/index.php/JMIJayakarta/article/view/498

[14] Maulia Usnaini, Verdi Yasin, Anton Zulkarnain Sianipar (2021), Perancangan sistem informasi inventarisasi aset berbasis web menggunakan metode waterfall, "Jurnal Manajemen Informatika Jayakarta”, E-ISSN : 2797-0930 (Online), P-ISSN : 2746-5985 (Print) Volume 1, Nomor 1,Februari 2021, halaman 36-55, DOI: 10.52362/jmijayakarta.v1i1.415, URL Publikasi: http://journal.stmikjayakarta.ac.id/index.php/JMIJayakarta/article/view/415

[15] Putri Setiani, Ifan Junaedi, Anton Zulkarnain Sianipar, Verdi Yasin (2021), Perancangan sistem informasi pelayanan penduduk berbasis website di rw 010 Kelurahan Keagungan Kecamatan Tamansari - Jakarta Barat. "Jurnal Manajemen Informatika Jayakarta", E-ISSN : 2797-0930 (Online), P-ISSN : 27465985 (Print) Volume 1, Nomor 1,Februari 2021, halaman 20-35, DOI: 10.52362/jmijayakarta.v1i1.414, URL Publikasi: http://journal.stmikjayakarta.ac.id/index.php/JMIJayakarta/article/view/414

[16] Benni Triyono, Sri Purwanti, Verdi Yasin (2017) "Rekayasa Perangkat Lunak Sistem Informasi Pengiriman Dan Penerimaan Surat Atau Paket Berbasis Web", Journal of Information System, Applied, Management, Accounting and Research, e-ISSN: 2598-8719. p-ISSN: 2598-8700.Vol.1 No.1 (30 Desember 2017) p46-53 http://journal.stmikjayakarta.ac.id/index.php/jisamar/article/view/12

[17] Verdi Yasin, Muhammad Zarlis, Mahyuddin K.M. Nasution (2018) "Filsafat Logika Dan Ontologi Ilmu Komputer”, Journal of Information System, Applied, Management, Accounting and Research, eISSN: 2598-8719. p-ISSN: 2598-8700.Vol.2 No.2 (19 Juni 2018) p68-75 http://journal.stmikjayakarta.ac.id/index.php/jisamar/article/view/39

[18] Julinda Maya Paramudita, Verdi Yasin (2019) "Perancangan Aplikasi Sistem Penyewaan Alat Berat ", Journal of Information System, Applied, Management, Accounting and Research, e-ISSN: 25988719. p-ISSN: 2598-8700.Vol.3 No.1 (20 Februari 2019) p23-29 http://journal.stmikjayakarta.ac.id/index.php/jisamar/article/view/73

[19] Muryan Awaludin, Verdi Yasin (2020) “Application Of Oriented Fast And Rotated Brief (Orb) And Bruteforce Hamming In Library Opencv For Classification Of Plants", Journal of Information System, Applied, Management, Accounting and Research, e-ISSN: 2598-8719. p-ISSN: 2598-8700.Vol.4 No.3 (14 Agustus 2020) p51-59 http://journal.stmikjayakarta.ac.id/index.php/jisamar/article/view/247

[20] Ifan Junaedi, Dimas Abdillah, Verdi Yasin (2020) "Analisis Perancangan Dan Pembangunan Aplikasi Business Intelligence Penerimaan Negara Bukan Pajak Kementerian Keuangan RI”, Journal of Information System, Applied, Management, Accounting and Research, e-ISSN: 2598-8719. p-ISSN: 2598-8700.Vol.4 No.3 (14 Agustus 2020) p88-101 http://journal.stmikjayakarta.ac.id/index.php/jisamar/article/view/249

[21] Verdi Yasin (2012) 'Rekayasa Perangkat Lunak Berorientasi Objek”, Penerbit: Mitra Wacana Media, Jakarta-Indonesia.

[22] Anis Rohmadi, Verdi Yasin (2020) "Desain Dan Penerapan Website Tata Kelola Percetakan Pada CV Apicdesign Kreasindo Jakarta Dengan Metode Prototyping”, Journal of Information System, Informatics and Computing._E-ISSN: 2597-3673 (Online), P-ISSN: 2579-5201 (Print) Vol. 4 No.1, June 22, 2020. Pp.70-85 http://journal.stmikjayakarta.ac.id/index.php/jisicom/article/view/210

[23] Septian Cahyadi, Verdi Yasin, Mohammad Narji, Anton Zulkarnain Sianipar (2020) "Perancangan Sistem Informasi Pengiriman Dan Penerimaan Soal Ujian Berbasis Web ( Studi Kasus: Fakultas Komputer Universitas Bung Karno)", Journal of Information System, Informatics and Computing._E-ISSN: 2597-3673 (Online), P-ISSN: 2579-5201 (Print) Vol. 4 No.1, June 22, 2020. Pp.1-16 http://journal.stmikjayakarta.ac.id/index.php/jisicom/article/view/199

[24] Ifan Junaedi, Ndaru Nuswantari, Verdi Yasin (2019) "Perancangan Dan Implementasi Algoritma C4.5 Untuk Data Mining Analisis Tingkat Risiko Kematian Neonatum Pada Bayi”, Journal of Information System, Informatics and Computing._E-ISSN: 2597-3673 (Online), P-ISSN: 2579-5201 (Print) Vol. 3 No.1, February 13, 2019. Pp.29-44. http://journal.stmikjayakarta.ac.id/index.php/jisicom/article/view/203

[25] Verdi Yasin, Anindra Ramdhan Nugraha, Muhammad Zarlis, Ifan Junaedi (2018) "Smart System Of Fast Internet Access Development Using Backbone Network Method”, Journal of Information System, Informatics and Computing._E-ISSN: 2597-3673 (Online), P-ISSN: 2579-5201 (Print) Vol. 2 No. 2 , 
December 31, 2018. Pp.26-34. http://journal.stmikjayakarta.ac.id/index.php/jisicom/article/view/198

[26] Ito Riris Immasari, Verdi Yasin (2019) "Penggunaan Metode Analytic Hierarchy Process Untuk Menganalisis Faktor-Faktor Yang Mempengaruhi Pemilihan Calon Legislatif Di Dprd Ii Kota Tangerang”, Journal of Information System, Informatics and Computing. E-ISSN: 2597-3673 (Online), P-ISSN: 2579-5201 (Print) Vol. 3 No. 2, December 10, 2019. Pp.53-58. http://journal.stmikjayakarta.ac.id/index.php/jisicom/article/view/139

[27] Verdi Yasin, Muhammad Zarlis, Tulus, Erna Budhiarti Nababan, Poltak Sihombing (2019) "Rancangan Miniatur Otomatisasi Bel Listrik Pada Gerbang Pintu Menggunakan Microkontroler Atmega8535", Journal of Information System, Informatics and Computing. E-ISSN: 2597-3673 (Online), P-ISSN: 2579-5201 (Print) Vol. 3 No. 1, February 13, 2019. Pp.13-20 http://journal.stmikjayakarta.ac.id/index.php/jisicom/article/view/68

[28] Anggeri S. Nurjaman, Verdi Yasin (2020) "Konsep Desain Aplikasi Sistem Manajemen Kepegawaian Berbasis Web Pada PT. Bintang Komunikasi Utama ”, Journal of Information System, Informatics and Computing. E-ISSN: 2597-3673 (Online), P-ISSN: 2579-5201 (Print) Vol. 4 No. 2, December 28, 2020. Pp.143-174_ http://journal.stmikjayakarta.ac.id/index.php/jisicom/article/view/363

[29] Verdi Yasin, Azhar Ahmad Riza, Rumadi Hartawan (2017) "Pengembangan Aplikasi Pemulihan Layanan Bencana Sistem Informasi Peneriman Negara Bukan Pajak Online Di Lingkungan Kementerian Keuangan Republik Indonesia", Journal of Information System, Informatics and Computing. E-ISSN: $2597-$ 3673 (Online), P-ISSN: 2579-5201 (Print) Vol. 1 No. 1, September 20, 2017. Pp.33-56. http://journal.stmikjayakarta.ac.id/index.php/jisicom/article/view/4 